\title{
Predicted vs. Actual Resting Energy Expenditure and Activity Coefficients: Post-Gastric Bypass, Lean and Obese Women
}

\author{
Farah A. Ramirez-Marrero ${ }^{1 *}$, Kim L. Edens ${ }^{2}$, Michael J. Joyner ${ }^{3}$ and Timothy B. \\ Curry $^{3}$ \\ ${ }^{1}$ Physical Education and Exercise Sciences, University of Puerto Rico, Rio Piedras, Puerto Rico \\ ${ }^{2}$ Endocrine Research Unit, Mayo Clinic, Rochester, Minnesota, USA \\ ${ }^{3}$ College of Medicine, Mayo Clinic, Rochester, Minnesota, USA
}

Received: July 16, 2014; Accepted: August 29, 2014; Published: September 16, 2014

*Corresponding author: Farah A. Ramirez-Marrero, Professor of Physical Education and Exercise Sciences, University of Puerto Rico, Rio Piedras, 23311, San Juan, Puerto Rico, 00931-3311, Tel: 787-764-0000, ext: 2921; Fax: 787-763-4711; E-mail: farah.ramirez1@upr.edu

\begin{abstract}
Total Energy Expenditure (TEE) and energy requirements are commonly estimated from equations predicting Resting Energy Expenditure (REE) multiplied by a Physical Activity (PA) coefficient that accounts for both PA energy expenditure and the thermogenic effect of food. PA coefficients based on PA self-reports are a potential source of error that has not been evaluated. Therefore, in this study we compared: 1) the Harris-Benedict (HB), Mifflin-St. Jeor (MSJ), and the Food and Agriculture Organization/World Health Organization/ United Nations University (FAO/WHO/UNU) REE equations with REE measured (REE-m) with indirect calorimetry; 2) PA coefficients determined with PA self-reports vs. objectively assessed PA; and 3) TEE estimates in post-Gastric Bypass ( GB = 13), lean ( $\mathrm{LE}=7$ ), and obese $(\mathrm{OB}=12)$ women. REE was measured in the morning after an overnight fast with participants resting supine for $30 \mathrm{~min}$. Selfreported PA was evaluated with a questionnaire and objectively measured with accelerometers worn for 5-7 days. Nutritional intake was evaluated with a food frequency questionnaire. Anthropometry included DEXA, and abdominal CT scans. Eligible GB had surgery $\geq$ 12 months before the study, and had $\geq 10 \mathrm{~kg}$ of body weight loss. All participants were 18-45 years of age, able to engage in ambulatory activities, and not taking part in exercise training programs. Oneway ANOVA was used to detect differences in REE and TEE. Accuracy of REE prediction equations were determined by cases within $10 \%$ of REE-m, and agreement analyses. REE predictions were not different than REE-m, but agreements were better with $\mathrm{HB}$ and MSJ, particularly in the GB and LE groups. Discrepancies in the PA coefficients determined with self-report vs. objectively assessed PA resulted in TEE overestimates (approximately 200-300 Kcal/day) using $\mathrm{HB}$ and MSJ equations. FAO/WHO/UNU overestimated TEE in all groups regardless of the PA assessment method (approximately 300-900 kcal/day). These results suggest that: 1) HB and MSJ equations are good predictors of REE among GB and LE, but not among OB women, 2) PA coefficients used to estimate TEE must be determined with objective PA assessment, and 3) TEE estimates using PA coefficients with the FAO/WHO/UNU equation must be used with caution.
\end{abstract}

Keywords: Energy requirements; Bariatric; Accelerometer; Indirect calorimetry

\section{Introduction}

Determining daily energy requirements to help guide weight control involves all components of Total Energy Expenditure (TEE): Resting Energy Expenditure (REE), Physical Activity Energy Expenditure (PAEE), and the Thermogenic Effect of Food (TEF). However, precise measurement of TEE mandates sophisticated equipment not readily available outside research or clinical settings.

The Harris-Benedict (HB), [1] Mifflin St. Jeor (MSJ), [2] and the Food and Agriculture Organization/ World Health Organization/ United Nations University (FAO/WHO/UNU)[3] are REE predicting equations widely used in different populations [4-6]. These equations consider factors such as weight, height, age, and gender. The predicted REE is then multiplied by a PA coefficient for an estimate of TEE (Table 1). These coefficients have been derived by subtracting REE measured with indirect calorimetry from the TEE measured with the doubly labelled water technique $[3,7,8]$. Therefore, PA coefficients account not only for PAEE but also the TEF. However, there are inconsistencies in the selection and recommendation of PA coefficients for different equations (Table 1). Specific PA coefficients are based on the PA level of each participant, usually determined by self-reports and dietitian's experience. Because PAEE is the most variable component of TEE, the impact of PA coefficients based on self-report vs. objective PA assessment must be evaluated.

After gastric bypass surgery REE declines in direct association with weight loss [9-11], and REE prediction equations remain well correlated with measured REE (REE-m) in this population. Flancbaum et al. [12] showed that HB equation predicted 90$101 \%$ of the REE-m by indirect calorimetry from pre- to 6-months post-surgery and $107-111 \%$ from $12-24$ months post-surgery; during which gastric bypass patient's weight decreased 96 to $146 \mathrm{~kg}$. Among obese individuals, Prado-de Oliveira et al. [13] reported that HB equation predicted REE-m; however, prediction was $8 \%$ lower. More recently, Ullah et al. [14] observed that HB equation overestimated REE by $10 \%$ in morbidly obese adults, 
but after gastric bypass surgery the difference was reduced to $1 \%$. Other studies have supported HB and MSJ equations to predict REE in non-obese to morbidly obese women [5,15], while the FAO/WHO/UNU equation have been supported by some [16] but criticized by others [15].

The HB, MSJ, and FAO/WHO/UNU equations to predict TEE using recommended PA coefficients in post-Gastric Bypass (GB), Lean (LE), and Obese (OB) adults have not been reported. Because the significant weight reduction after gastric bypass surgery represents a metabolic challenge not fully understood, and because over reporting PA behavior is common, particularly among overweight and obese adults $[17,18]$, we hypothesized that 1) predicted REE will be similar to REE-m using all equations, but 2) differences in PA coefficients determined with self-report vs. objectively assessed PA behavior will be present among GB, LE, and OB women.

\section{Methods}

A sub-group of non-diabetic female adults were recruited from a larger study [4]: GB ( $n=13)$, LE $(n=7)$, and OB $(n=12)$. GB participants were contacted from a database of patients that had undergone open or laparoscopic proximal Roux-en-Y gastric bypass surgery at Mayo Clinic, Rochester, MN. The eligibility criteria were: $18-45$ years of age, surgery $\geq 12$ months prior to the study, $\geq 10 \mathrm{~kg}$ of body weight loss, and able to engage in ambulatory activities. Women were specifically targeted in the present study due to the fact that more that $80 \%$ of bariatric surgery patients are women [19]. Participants in the OB and LE groups were recruited from the surrounding Rochester, MN, area through advertisements. All participants underwent a medical history and physical exam by a study physician, had a confirmed negative pregnancy test, and were evaluated during the early follicular phase of the menstrual cycle or during days 3-7 of the

Table 1: Equations to predict Resting Energy Expenditure and recommended Physical Activity (PA) coefficients for each PA level.

\begin{tabular}{|c|c|c|}
\hline \multicolumn{2}{|r|}{ Equation } & $\begin{array}{c}\text { PA Level: } \\
\text { PA } \\
\text { Coefficient }\end{array}$ \\
\hline $\begin{array}{l}\text { HB } \\
(1984)\end{array}$ & $\begin{array}{l}\text { Women }(\text { REE })=447.593 \times(9.247 \times \text { weight })+ \\
(3.098 \times \text { height })-(4.330 \times \text { age })\end{array}$ & \multirow{2}{*}{$\begin{array}{l}0: 1.2 \\
1: 1.375 \\
2: 1.55 \\
3: 1.725 \\
4: 1.9\end{array}$} \\
\hline $\begin{array}{l}\text { MSJ } \\
(2005)\end{array}$ & $\begin{array}{l}\text { Women }(\text { REE })=(9.99 \times \text { weight })+6.25 \times \\
\text { height })-(4.92 \times \text { age })-161\end{array}$ & \\
\hline $\begin{array}{l}\text { FAO/ } \\
\text { WHO/ } \\
\text { UNU } \\
(1985)\end{array}$ & $\begin{array}{l}\text { Women - (REE by age group }) \\
18-30 \text { yr. of age: }(13.3 \times \text { weight })+(334 \times \text { height }) \\
+35 \\
31-60 \text { yr. of age: }(8.7 \times \text { weight })-(25 \times \text { height })+ \\
885 \\
>60 \text { yr. of age: }(9.2 \times \text { weight })+(637 \times \text { height })- \\
302\end{array}$ & $\begin{array}{l}0: 1.56 \\
1: 1.64 \\
2: 1.82\end{array}$ \\
\hline
\end{tabular}

$\mathrm{HB}=$ Harris-Benedict, $\mathrm{MSJ}=$ Mifflin-St. Jeor, FAO/WHO/UNU = World Health Organization/Food and Agriculture Organization/United Nations University. Weight in $\mathrm{kg}$, Height in $\mathrm{cm}$ (m for FAO/WHO/UNU), and Age in years.

PA level for HB and MSJ: $0=$ little or no exercise, 1 = light exercise, 2 = moderate exercise, 3 = heavy exercise, 4 = very heavy exercise. PA level in FAO/WHO/UNU is based on occupational activity: 0 = light activity, 1 = moderate activity, and 2 = heavy activity. placebo phase of oral contraceptive therapy. Participants taking part in exercise training programs were excluded. The Mayo Institutional Review Board approved the study and participants gave informed consent after all their questions were answered. All testing were conducted at the Clinical Research Unit of the Mayo Clinic Center for Translational Science Activities.

\section{REE}

REE was measured over 30 min using indirect calorimetry (Deltatrack, Sensormedics, Yorba Linda, CA). Measurements were taken during the same time of the day (starting at 7:00 am) with participants in fasting state lying in a supine position with care taken to minimize distractions. Heart rate was measured from a 3-lead ECG. Predicted REE was determined using the HB, MSJ and FAO/WHO/UNU equations (Table 1).

\section{Physical activity and sedentary behavior}

Self-reported PA was assessed through personal interviews using the International PA Questionnaire (IPAQ), where min/ week of Moderate to Vigorous Physical Activities (MVPA) and sitting or sedentary time were determined. Objective PA and sedentary time was obtained using the ActiGraph GT1M accelerometer attached to an elastic belt and worn at the hip level for 5-7 consecutive days including at least one weekend day. Participants were instructed to remove the accelerometer only when showering, sleeping at night, or engaging in aquatic activities. Daily phone calls helped ensure proper use of accelerometers, which were fully charged and set for 60 second epoch of activity count and steps measurements. Participants were scheduled for a visit to complete the IPAQ and return the accelerometer for downloading (ActiLife v4.4.1, The ActiGraph, Pensacola, Florida) and assessment of MVPA, sedentary time, and steps/day using previously reported protocols [20-22].

\section{Physical activity level and coefficient}

PA levels were determined using the following categories: $0=$ little or no exercise, 1 = light, 2 = moderate, 3 = heavy and 4 = very heavy exercise; in accordance to PA categories recommended for the HB equation [7]. A PA level was assigned to each participant based on their self-reported and accelerometer determined MVPA in min/day and steps/day using previously described thresholds [20-22]: $0 \leq 100 \mathrm{~min} /$ week or $<5,000$ steps/day, $1=100-149$ $\mathrm{min} /$ week or 5,000-7,499 steps/day, $2=150-299 \mathrm{~min} /$ week or 7,500-9,999 steps/day, $3=300-449 \mathrm{~min} /$ week or 10,000-12,000 steps/day, and $4 \geq 450 \mathrm{~min} /$ week or $\geq 12,500$ steps/day.

The recommended PA coefficient [7] for each PA level (Table 1) was multiplied by the REE predicted with HB and MSJ equations for an estimate of TEE. The FAO/WHO/UNU equation presents a different set of PA levels and coefficient (FAO/WHO/ UNU, 1985) which were determined according to the following criteria: 0 (light activity) $<150 \mathrm{~min} /$ week or $<7,500$ steps/day, 1 (moderate activity) $=150-299 \mathrm{~min} /$ week or $7,500-10,000$ steps/day, and 2 (heavy activity) $\geq 300 \mathrm{~min} /$ week or $\geq 10,000$ steps/day. We also determined TEE for each participant using the REE- $\mathrm{m}$, the accelerometer determined PAEE, and $10 \%$ for the TEF. Then, we determined a PA coefficient by dividing our determined TEE by the REE-m (Table 2). 


\section{Body composition}

Body composition was determined with DEXA (DPX-IQ, GE Medical Systems Lunar Corporation, Madison, WI). Abdominal (L2 vertebrae level) 6-10 $\mathrm{mm}$ sectional slices were obtained from CT scans; and the amount of adipose tissue determined automatically using a seeding program as previously described [23]. Body mass index (BMI: $\mathrm{kg} / \mathrm{m}^{2}$ ) was calculated from height $(\mathrm{cm})$ and weight $(\mathrm{kg})$ using a Cardinal/Detecto scale (Webb City, Missouri). A registered nurse took all measurements.

\section{Nutritional intake}

The general Viocare Technologies electronic food frequency questionnaire (Vio-FFQ) was administered by interview. This instrument capture the previous 30-day average nutritional intake employing the Minnesota nutritional database for analyses, and has been validated against 4-day food records and 24-hr dietary recalls [24].

\section{Data analyses}

Statistical analyses included means and standard errors for all study variables. A one-way ANOVA was used to determine differences between REE-m and predicted with HB, MSJ, and FAO/WHO/UNU equations, and agreements between REE-m and predicted were evaluated with Bland \& Altman's plots [25] In addition, the concordance correlation coefficient and mean difference for each group were obtained to further test the agreement between the REE-m and predicted [26]. The percent REE predicted with each equation was also determined. One-way ANOVAs were used to determine differences in PA coefficients within each group based on self-reported and objectively assessed PA behavior, and differences in TEE estimated with self-reported and objectively assessed PA coefficients. Statistical significance was interpreted from a $p<0.05$ using STATA (version 11, 2009, STATA Corp LP, College Station, TX).

\section{Results}

Average BMI for GB participants at the time of surgery was $44.7 \pm 1.0 \mathrm{~kg} / \mathrm{m}^{2}$, and time from surgery to the study was $38 \pm 5$ months, with an average loss of $33 \pm 2 \%$ of pre-surgical weight. General physical and nutritional characteristics are presented in Table 3. Groups were similar in age, fat free mass, REE relative to fat free mass, MVPA, and sedentary time. Resting oxygen consumption relative to body weight was lower and PAEE higher in OB compared with GB and LE groups. BMI was different between groups with $\mathrm{OB}$ having the highest and LE having the lowest values. Nutritional intakes were similar between groups.

No within group differences were observed for REE-m and predicted with the three equations, but between group differences were detected. REE-m was lower in LE compared with the GB and OB groups, and predicted REE were different between the three groups (Figure 1A), with the highest predicted REE observed in the $\mathrm{OB}$ and the lowest in the LE group. The percent of REE predicted with all equations was higher in the OB compared with the GB group (Figure 1B). Moreover, the agreement and concordance between the REE-m and predicted with HB, MSJ, and $\mathrm{FAO} / \mathrm{WHO} / \mathrm{UNU}$ equations (Figure 2A, 2B, 2C, respectively)
Table 2: General physical and nutrition characteristics of study participants (Mean \pm SE).

\begin{tabular}{|c|c|c|c|c|}
\hline Variable & GB $(n=13)$ & LE $(n=7)$ & OB $(n=12)$ & $\mathbf{P}$ \\
\hline Age (yrs.) & $7.6 \pm 1.7$ & $36.6 \pm 2.7$ & $32.0 \pm 2.3$ & 0.14 \\
\hline BMI $\left(\mathrm{kg} / \mathrm{m}^{2}\right)$ & $30.2 \pm 1.4^{*}$ & $22.4 \pm 0.8^{*}$ & $37.9 \pm 1.0^{*}$ & $\begin{array}{c}< \\
0.001\end{array}$ \\
\hline Visceral fat $\left(\mathrm{cm}^{2}\right)$ & $58.8 \pm 10.5$ & $31.4 \pm 8.7$ & $\begin{array}{l}127.4 \pm \\
11.0^{*}\end{array}$ & 0.005 \\
\hline Fat Free Mass (kg) & $5.2 \pm 1.7$ & $42.4 \pm 2.4$ & $49.8 \pm 1.8$ & 0.06 \\
\hline $\begin{array}{l}\text { Resting } \mathrm{VO}_{2}\left(\mathrm{ml} \cdot \mathrm{kg}^{-}\right. \\
\left.{ }^{1} \cdot \mathrm{min}^{-1}\right)\end{array}$ & $2.24 \pm 0.1$ & $2.44 \pm 0.1$ & $1.95 \pm 0.1^{*}$ & 0.002 \\
\hline $\begin{array}{l}\text { Relative REE (kcal/kg } \\
\text { FFM) }\end{array}$ & $35.6 \pm 1.2$ & $32.7 \pm 1.8$ & $35.1 \pm 1.6$ & 0.45 \\
\hline $\begin{array}{l}\text { Accelerometer Total } \\
\text { MVPA (min/week) }\end{array}$ & $\begin{array}{c}185.9 \pm \\
33.0\end{array}$ & $\begin{array}{l}322.6 \pm \\
136.3\end{array}$ & $\begin{array}{c}124.0 \pm \\
22.1\end{array}$ & 0.09 \\
\hline $\begin{array}{l}\text { MVPA in } 10 \text { min bouts } \\
\text { (min/week) }\end{array}$ & $22.9 \pm 11.4$ & $\begin{array}{l}174.4 \pm \\
133.2\end{array}$ & 7.3 & 0.10 \\
\hline $\begin{array}{l}\text { Accelerometer PAEE } \\
\text { (kcal) }\end{array}$ & $\begin{array}{c}268.8 \pm \\
19.4\end{array}$ & $179.4 \pm 26.8$ & $\begin{array}{l}350.4 \pm \\
24.2^{*}\end{array}$ & 0.002 \\
\hline $\begin{array}{l}\text { Accelerometer } \\
\text { Sedentary Time (hrs./ } \\
\text { day) }\end{array}$ & $9.7 \pm 0.5$ & $9.3 \pm 0.7$ & $9.9 \pm 0.5$ & 0.78 \\
\hline IPAQ MVPA (min/week) & $\begin{array}{l}497.7 \pm \\
248.6\end{array}$ & $\begin{array}{l}541.4 \pm \\
263.7\end{array}$ & $\begin{array}{c}828.6 \pm \\
261.7\end{array}$ & 0.61 \\
\hline $\begin{array}{l}\text { IPAQ Sedentary Time } \\
\text { (hrs./day) }\end{array}$ & $7.9 \pm 1.4$ & $6.7 \pm 1.1$ & $7.7 \pm 0.9$ & 0.81 \\
\hline Energy Intake (kcal/day) & $\begin{array}{l}1878 \pm \\
215.7\end{array}$ & $\begin{array}{c}1697 \pm \\
335.1\end{array}$ & $\begin{array}{c}2119 \pm \\
476.0\end{array}$ & 0.75 \\
\hline Carbohydrate Intake (g) & $\begin{array}{l}225.6 \pm \\
27.3\end{array}$ & $208.7 \pm 47.8$ & $\begin{array}{c}244.6 \pm \\
48.8\end{array}$ & 0.85 \\
\hline Fat Intake (g) & $77.0 \pm 10.8$ & $59.4 \pm 9.4$ & $83.5 \pm 19.9$ & 0.61 \\
\hline Protein Intake (g) & $76.5 \pm 7.7$ & $78.1 \pm 19.1$ & $94.0 \pm 19.2$ & 0.66 \\
\hline
\end{tabular}

* Values significantly different from each other (BMI = Body Mass Index, MVPA = Moderate to Vigorous PA, REE $=$ Resting Energy Expenditure, PAEE = PA Energy Expenditure, IPAQ = International PA Questionnaire)

was similar for all groups combined (coefficient of concordance: $0.75,0.75$, and 0.72 , respectively; $p<0.001$ for all). However, when groups were analyzed individually (dashed lines in Figure 2 ), the coefficient of concordance remained significant with all equations for the GB and LE groups, but not significant for the $\mathrm{OB}$ group. Figure 2 also shows a tendency for REE predicted to be higher at higher levels and lower at lower levels of REE-m. This tendency disappeared when all groups were combined.

PA coefficients using objective vs. self-reported PA level are presented in Table 3. Values were higher using the FAO/WHO/ UNU classification and, as expected, values were also higher when using self-reports to classify PA level. Our determined PA coefficient was similar to PA coefficients estimated with objectively assessed PA level. Although the differences between PA coefficients appeared small, when values were used to predict TEE, differences in energy requirements were magnified. The comparison between our determined TEE and TEE predicted with each equation is presented in Figure 3. No differences were observed between these two values in GB and OB groups when objective PA level and coefficients were used, but predicted TEE was higher with self-reported PA level (approximately 
200-300 Kcal/day). In the LE group, TEE predicted with HB was higher (approximately $300 \mathrm{Kcal} /$ day) with both objectively and subjectively determined PA level. Predicted TEE with MSJ equation was similar to our determined TEE in all groups when using objectively and subjectively determined PA level. With the FAO/WHO/UNU equation, the predicted TEE was significantly higher (approximately $300-900 \mathrm{kcal} /$ day) in all groups regardless of how PA level was determined.

\section{Discussion}

In this study we compared 1) REE measured and predicted with $\mathrm{HB}, \mathrm{MSJ}$, and FAO/WHO/UNU equations, and 2) our determined PA coefficient with those commonly used for $\mathrm{HB}$, MSL, and FAO/WHO/UNU equations, and 3) our determined TEE and TEE predicted for GB, LE, and $\mathrm{OB}$ women. The most important findings are: REE predicted using $\mathrm{HB}, \mathrm{MSJ}$, and FAO/WHO/UNU equations were not different than REE-m, and the agreement and concordance between REE-m and predicted was significant for all groups combined. However, the limits of agreement and concordance between REE-m and predicted for each individual group were not acceptable only in the OB group; thus, suggesting that HB and MSJ equations are adequate to predict REE in GB and LE but not in OB women. We also observed that equations tended to overestimate in the lower range and underestimate in the higher range of REE in the GB and LE groups. Another important finding is that PA levels determined with self-reports resulted in elevated PA coefficients that magnified the TEE predicted, particularly with the FAO/WHO/UNU equation. Therefore, the selection of PA coefficients to predict TEE should be based on objective assessments of PA using accelerometers.

Table 3: Mean and range of recommended physical activity (PA) coefficients as determined by individual PA levels obtained by objective assessment (steps/day or accelerometer-MVPA) or self-reported (IPAQ) PA behavior, and determined PA coefficient based on objective measurements in post-gastric bypass (GB), Lean (LE) and Obese (OB) women.

\begin{tabular}{|c|c|c|c|c|}
\hline Criteria & Equation & GB & LE & OB \\
\hline \multirow{2}{*}{ Steps/day } & HB, MSJ & $\begin{array}{c}1.4 \\
(1.2-1.725)\end{array}$ & $\begin{array}{c}1.5 \\
(1.2-1.9)\end{array}$ & $\begin{array}{c}1.4 \\
(1.2-1.55)\end{array}$ \\
\hline & $\begin{array}{c}\text { FAO/WHO/ } \\
\text { UNU }\end{array}$ & $\begin{array}{c}1.6 \\
(1.56-1.64)\end{array}$ & $\begin{array}{c}1.6 \\
(1.5-1.82)\end{array}$ & $\begin{array}{c}1.6 \\
(1.56-1.64)\end{array}$ \\
\hline \multirow{2}{*}{$\begin{array}{l}\text { Accelerom- } \\
\text { eter - MVPA } \\
\text { (min/week) }\end{array}$} & HB, MSJ & $\begin{array}{c}1.4 \\
(1.2-1.9)\end{array}$ & $\begin{array}{c}1.5 \\
(1.2-1.9)\end{array}$ & $\begin{array}{c}1.3 \\
(1.2-1.55)\end{array}$ \\
\hline & $\begin{array}{c}\text { FAO/WHO/ } \\
\text { UNU }\end{array}$ & $\begin{array}{c}1.6 \\
(1.56-1.82)\end{array}$ & $\begin{array}{c}1.7 \\
(1.56-1.82)\end{array}$ & $\begin{array}{c}1.6 \\
(1.56-1.64)\end{array}$ \\
\hline \multirow{2}{*}{$\begin{array}{l}\text { IPAQ - MVPA } \\
\text { (min/week) }\end{array}$} & $\mathrm{HB}, \mathrm{MSJ}$ & $\begin{array}{c}1.6 \\
(1.2-1.9)\end{array}$ & $\begin{array}{c}1.5 \\
(1.2-1.725)\end{array}$ & $\begin{array}{c}1.5 \\
(1.2-1.725)\end{array}$ \\
\hline & $\begin{array}{c}\text { FAO/WHO/ } \\
\text { UNU }\end{array}$ & $\begin{array}{c}1.7 \\
(1.56-1.82)\end{array}$ & $\begin{array}{c}1.6 \\
(1.56-1.82)\end{array}$ & $\begin{array}{c}1.6 \\
(1.56-1.82)\end{array}$ \\
\hline \multicolumn{2}{|c|}{$\begin{array}{l}\text { Determined PA coefficient } \\
=(\text { REE-m + accelerometer } \\
\text { PAEE + TEF }) / \text { REE-m }\end{array}$} & $\begin{array}{c}1.4 \\
(1.3-1.5)\end{array}$ & $\begin{array}{c}1.3 \\
(1.2-1.4)\end{array}$ & $\begin{array}{c}1.4 \\
(1.3-1.6)\end{array}$ \\
\hline
\end{tabular}

Mean and range of recommended physical activity (PA) coefficients as determined by individual PA levels obtained by objective assessment (steps/day or accelerometer-MVPA) or self-reported (IPAQ) PA behavior, and determined PA coefficient based on objective measurements in postgastric bypass (GB), Lean (LE) and Obese (OB) women.

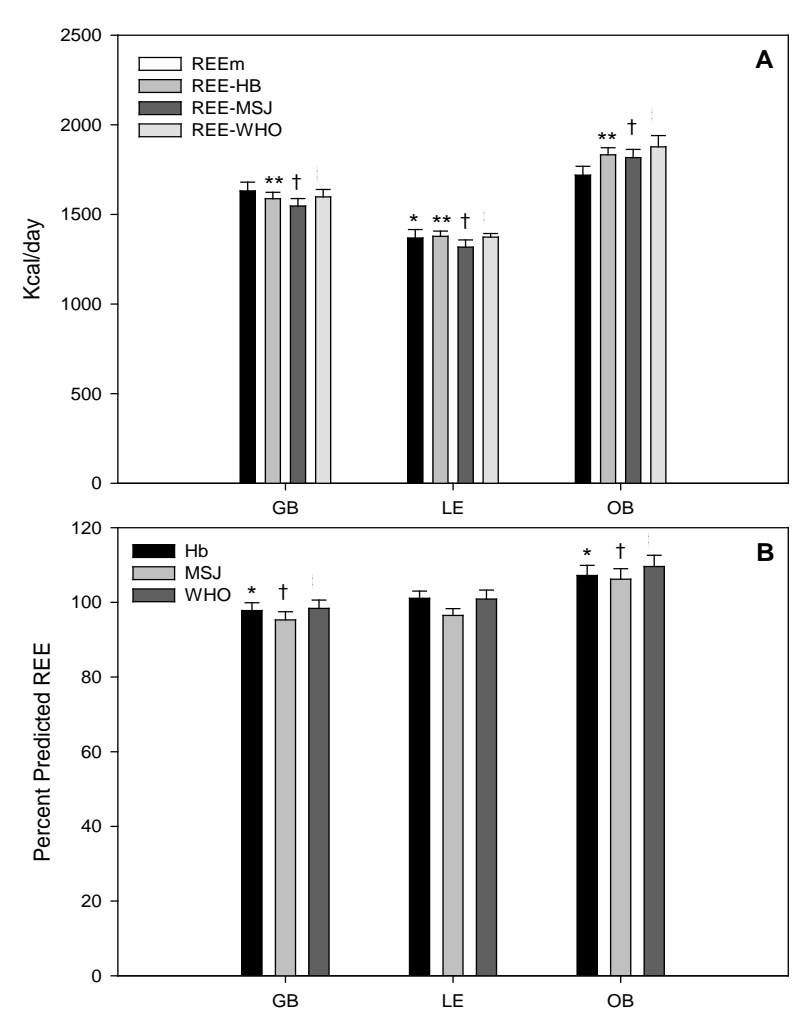

Figure 1: Resting energy expenditure (A) and percent of resting energy expenditure predicted (B) by Harris-Benedict (HB), Mifflin St. Jeor (MSJ), and FAO/WHO/UNU equations in post gastric-bypass (GB), Lean (LE) and Obese (OB) women (Between group: bars with same symbols are significantly different from each other, $\mathrm{P}<0.05$ ).

Previous studies have reported similar REE-m and predicted with $\mathrm{HB}, \mathrm{MSJ}$ and FAO/WHO/UNU equations [27,28], and a tendency for bias in REE predicted in the extremes of REE-m $[28,29]$. Although, this bias was not present in our OB group, their predicted REE had poor agreement and concordance with REE-m. Only $33 \%$ of the predicted REE in this group were within $10 \%$ of the REE-m using the FAO/WHO/UNU equation, and $50 \%$ with $\mathrm{HB}$ and MSJ equations, which is consistent with Spears et al. [28] observations However, 78-100\% of our GB and LE groups had predicted REE within $10 \%$ of the REE-m using all three equations.

A better REE estimate with MSJ compared with HB was reported in a systematic review among non-obese and obese adults [5]. REE predicted with MSJ was within $10 \%$ of the REE-m in $82 \%$ of non-obese, and $70 \%$ of obese participants, contrasting with REE predicted with HB which was accurate in $45-80 \%$ of the non-obese, and $38-66 \%$ of the obese. FAO/WHO/UNU equation was not included because of lack of evidence at the individual level at that time. However, in a study to determine energy requirements in a controlled feeding trial, Lin et al. [16] reported that $\mathrm{HB}$ and $\mathrm{FAO} / \mathrm{WHO} / \mathrm{UNU}$ equations accurately predicted energy requirements to achieve stable weight. In another study, Weijs and Vansant [15] evaluated the accuracy of $\mathrm{HB}, \mathrm{MSJ}$, and FAO/WHO/UNU equations among normal weight 
to morbidly obese Belgian women. Although the REE predicted and REE-m were similar (Mean $\pm \mathrm{SD}=1,687 \pm 219,1,614 \pm 247$, $1,691 \pm 240$, and $1,657 \pm 288 \mathrm{Kcal} /$ day, respectively), and the average accuracy was also similar $(68,68$, and $61 \%$ cases within $10 \%$ of REE-m, respectively); at the individual level the accuracy dropped significantly (51\% to $29 \%$ ) with the FAO/WHO/UNU in extremely obese women $\left(\geq 45 \mathrm{Kg} / \mathrm{m}^{2}\right)$. In the rage of BMI observed in our study the accuracy of the HB and MSJ equations reported by Weijs and Vansant [15] ranged from 75-80\%, which is also consistent with our results. These authors concluded that HB and MSJ can be used to predict REE in normal weight to
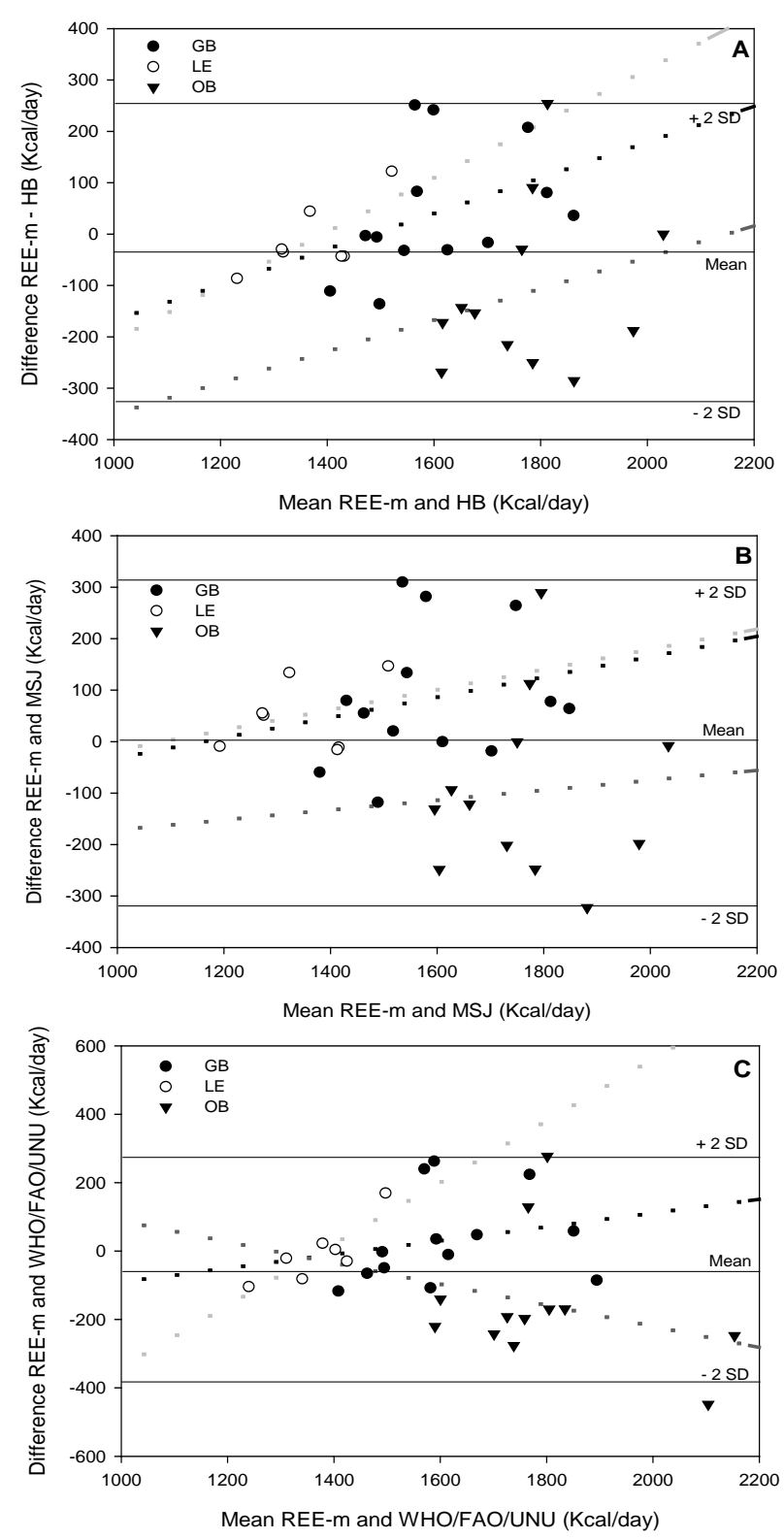

Figure 2: Agreement between REE measured and REE predicted by Harris-Benedict (HB: A), Mifflin St. Jeor (MSJ: B), and FAO/WHO/UNU (C) equations in post-gastric bypass (GB: black line), Lean (LE: light gray line), and Obese (OB: dark gray line).

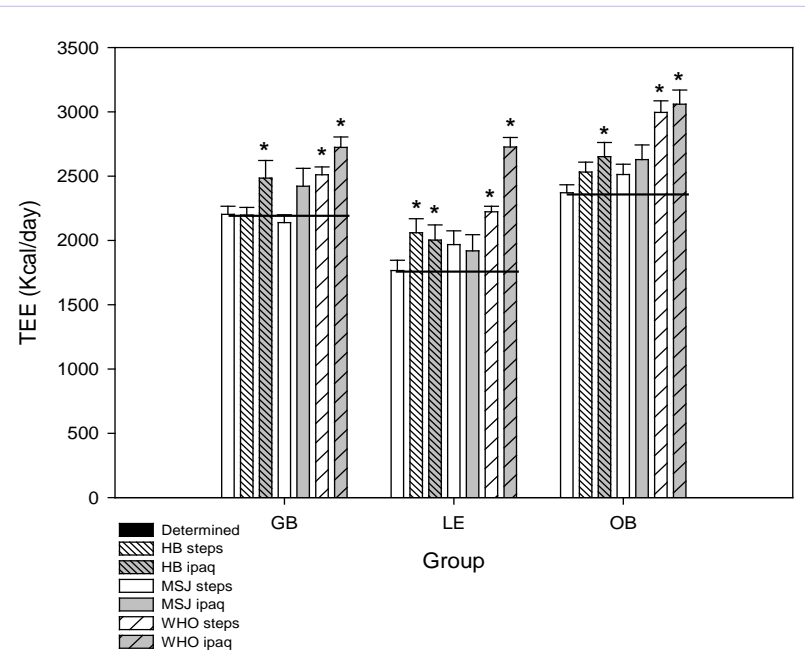

Figure 3: Total Energy Expenditure (TEE) as estimated and predicted by different equations using a physical activity coefficient based on selfreported (IPAQ) versus objective (steps/day) assessment of PA behavior in post-gastric bypass (GB), Lean (LE) and Obese (OB) women. $(* \mathrm{P}<$ 0.05 compared with determined TEE).

morbidly obese women. The present study is the first to provide these evaluations in women who have undergone gastric bypass surgery, and also the first to compare PA coefficients to estimate TEE based on objective vs. subjective assessment of PA level.

The use of PA coefficients to estimate TEE from REE prediction equations is common among dietitians and nutritionists when assessing energy requirements and nutritional interventions. The difficulties with the accuracy of these coefficients are partially solved when TEE is measured with doubly labelled water under free living conditions, and REE with indirect calorimetry [7]. PA coefficients derived from such measures account not only for the PAEE but also the TEF. Based on these reports, a mean 1.65 PA coefficient was derived, with lower coefficients for individuals classified as sedentary and low active (1.2-1.5), and higher values for individuals classified as heavily active (1.8-2.4) [30]. Other categories of PA and corresponding PA coefficients have been used (Table 1) in different studies. For example, Kien and Ugrasbul [31] used a standard PA coefficient of 1.6 for the estimate of TEE in non-obese adults; while Spears et al. [28] used a PA coefficient of 1.4 for sedentary, 1.5 for low active, and 1.6 for active overweight women. Others have failed to specify how PA level is determined or which PA coefficient is used to estimate TEE $[4,6]$. However, most studies rely on PA self-reports [6,16,28] which are likely to overestimate PA coefficients because of the usual over-reporting of PA behavior [18]. We recently reported that GB, LE and OB adults overestimate their PA behavior with self-reports compared with objective assessment, and the overestimation is higher in OB compared with GB and LE groups [17]. Light activity and sedentary behavior in the present group of women showed, as expected, that the proportion classified as sedentary to low active was lower with self-report compared with accelerometer (GB: 38 vs. 81\%; LE: 57 vs. 71\%; OB: 50 vs. $81 \%)$, and the level of sedentariness among these participants 
was of concern.

Our determined PA coefficients for GB, LE, and OB women were similar to those recommended for $\mathrm{HB}$ and MSJ only when using objectively assessed PA level, and were lower than coefficients for the FAO/WHO/UNU equation and coefficients used in previous studies [28,31]. These differences are magnified when coefficients are used to estimate TEE from prediction equations, particularly with the FAO/WHO/UNU, suggesting that their PA coefficients are probably inadequate. Overestimates of daily energy requirements ranging from $200-900 \mathrm{kcal} /$ day when adding an estimated PA coefficient factor to an REE prediction equation could jeopardize any attempt for weight control. It was also interesting to notice that energy intake was not different than our determined TEE in each group (GB= 1,878 \pm 215 vs. $2,203 \pm 62 \mathrm{Kcal} /$ day; $\mathrm{LE}=1,698 \pm 329$ vs. $1,767 \pm 78 \mathrm{Kcal} /$ day; OB $=2,199 \pm 481$ vs. $2,370 \pm 63 \mathrm{Kcal} /$ day, respectively), suggesting that women participants were likely in energy balance.

There are important limitations in the present study. First our small sample size consisting only of women makes our results not generalizable to men. However, our results are comparable to previous studies with women using larger sample sizes. A strength and novelty of this study is the inclusion of GB, LE, and $\mathrm{OB}$ groups for comparison. A second limitation is the lack of valid assessment of TEF. Although TEF represents a small amount of the TEE, assuming that it represents $10 \%$ of the TEE could be problematic for some individuals. There is limited information regarding TEF among GB, OB and LE individuals. The comparison of TEF before and after gastric bypass surgery have indicated either no change or $200 \%$ increase [11].

In conclusion, predictions of REE using HB and MSJ equations appeared adequate for our GB and LE women, but caution is advised for those in the extremes of REE. Among OB women HB and MSJ equations were less appropriate, and the FAO/WHO/ UNU equation was the least accurate in all groups. To determine daily energy requirements from estimated TEE, PA coefficients must be based on objectively assessed PA behavior. Future studies must include TEF among GB, LE and OB participants so that TEE prediction equations could be adequately validated.

\section{Disclaimers}

The authors have no financial conflicts to disclose. The views expressed in the submitted article are the authors' own and not an official position of the University of Puerto Rico or Mayo Clinic.

\section{Sources of support}

This work was supported in part by CTSA UL1-RR24150, and CTSA KL2-RR024151 from the National Institutes of Health, and the Mayo Clinic Department of Anesthesiology; and Title V grant P031S100037 from the Department of Education.

\section{References}

1. Roza AM, Shizgal HM. The Harris Benedict equation reevaluated: resting energy requirements and the body cell mass. Am J Clin Nutr. 1984; 40(1):168-182

2. Mifflin MD, St Jeor ST, Hill LA, Scott BJ, Daugherty SA, Koh YO. A new predictive equation for resting energy expenditure in healthy individuals. Am J Clin Nutr. 1990; 51(2):241-247.

3. FAO/WHO/UNU. Energy and Protein Requirements. 2005. Available at: http://www.fao.org/docrep/003/aa040e/aa040e00.htm

4. Curry TB, Somaraju M, Hines CN, Groenewald CB, Miles JM, Joyner MJ, et al. Sympathetic support of energy expenditure and sympathetic nervous system activity after gastric bypass surgery. Obesity (Silver Spring). 2013; 21(3):480-5. doi: 10.1002/oby.20106.

5. Frankenfield D, Roth-Yousey L, Compher C. Comparison of predictive equations for resting metabolic rate in healthy nonobese and obese adults: a systematic review. J Am Diet Assoc. 2005; 105(5):775-89.

6. Novais PF, Rasera I Jr, Leite CV, Marin FA, de Oliveira MR. Food intake in women two years or more after bariatric surgery meets adequate intake requirements. Nutrition Research 2012; 32(5):335-341.

7. Black AE, Coward WA, Cole TJ, Prentice AM. Human energy expenditure in affluent societies: an analysis of 574 doubly-labelled water measurements. Eur J Clin Nutr. 1996; 50(2):72-92.

8. Pullicino E, Goldberg GR, Elia M. Energy expenditure and substrate metabolism measured by $24 \mathrm{~h}$ whole-body calorimetry in patients receiving cyclic and continuous total parenteral nutrition. Clin Sci (Lond). 1991; 80(6):571-82.

9. Carrasco F, Papapietro K, Csendes A, Salazar G, Echenique C, Lisboa $\mathrm{C}$, et al. Changes in resting energy expenditure and body composition after weight loss following Roux-en-Y gastric bypass. Obes Surg. 2007; 17(5):608-16.

10. de Castro Cesar M, de Lima Montebelo MI, Rasera I Jr, de Oliveira AV Jr, Gomes Gonelli PR, Aparecida Cardoso G. Effects of Roux-en-Y gastric bypass on resting energy expenditure in women. Obes Surg. 2008; 18(11):1376-80. doi: 10.1007/s11695-008-9460-8.

11. Thivel D, Brakonieki K, Duche P, Morio B, Boirie Y, Laferrère B. Surgical weight loss: impact on energy expenditure. Obes Surg. 2013; 23(2):255-66. doi: 10.1007/s11695-012-0839-1.

12. Flancbaum L, Choban PS, Bradley LR, Burge JC. Changes in measured resting energy expenditure after Roux-en-Y gastric bypass for clinically severe obesity. Surgery. 1997; 122(5):943-9.

13. de Oliveira EP, Orsatti FL, Teixeira O, Maestá N, Burini RC. Comparison of predictive equations for resting energy expenditure in overweight and obese adults. J Obes. 2011; 2011:534714. doi: 10.1155/2011/534714.

14. Ullah S, Arsalani-Zadeh R, MacFie J. Accuracy of prediction equations for calculating resting energy expenditure in morbidly obese patients. Ann R Coll Surg Engl. 2012; 94(2):129-32. doi: 10.1308/003588412X1317122150 1988.

15. Weijs PJ, Vansant GA. Validity of predictive equations for resting energy expenditure in Belgian normal weight to morbid obese women. Clin Nutr. 2010; 29(3):347-51. doi: 10.1016/j.clnu.2009.09.009.

16. Lin PH, Proschan MA, Bray GA, Fernandez CP, Hoben K, MostWindhauser $\mathrm{M}$, et al. Estimation of energy requirements in a controlled feeding trial. Am J Clin Nutr. 2003; 77(3):639-45.

17. Ramirez-Marrero FA, Miles J, Joyner MJ, Curry TB. Self-reported and objective physical activity in postgastric bypass surgery, obese and lean adults: association with body composition and cardiorespiratory fitness. J Phys Act Health. 2014; 11(1):145-51. doi: 10.1123/jpah.2012-0048.

18. Shephard RJ. Limits to the measurement of habitual physical activity by questionnaires. Br J Sports Med 2003; 37(3):197-206 doi:10.1136/ bjsm.37.3.197. 
19. Samuel I, Mason EE, Renquist KE, Huang YH, Zimmerman MB, Jamal M. Bariatric surgery trends: an 18-year report from the International Bariatric Surgery Registry. Am J Surg. 2006; 192(5):657-62.

20. Freedson PS, Melanson E, Sirard J. Calibration of the Computer Science and Applications, Inc. accelerometer. Med Sci Sports Exerc. 1998; 30(5):777-81.

21. Troiano RP, Berrigan D, Dodd KW, Masse LC, Tilert T, McDowell M. Physical activity in the United States measured by accelerometer. Med Sci Sports Exerc. 2008; 40(1):181-8.

22. Tudor-Locke C, Hatano Y, Pangrazi RP, Kang M. Revisiting "how many steps are enough?”. Med Sci Sports Exerc. 2008; 40(7 Suppl):S537-43. doi: 10.1249/MSS.0b013e31817c7133

23. Jensen MD, Kanaley JA, Reed JE, Sheedy PF. Measurement of abdominal and visceral fat with computed tomography and dual-energy $\mathrm{x}$-ray absorptiometry. Am J Clin Nutr. 1995; 61(2):274-8.

24. Patterson RE, Kristal AR, Tinker LF, Carter RA, Bolton MP, Agurs-Collins T. Measurement characteristics of the Women's Health Initiative food frequency questionnaire. Ann Epidemiol. 1999; 9(3):178-87.

25. Bland JM, Altman DG. Statistical methods for assessing agreement between two methods of clinical measurement. Lancet1986; 1(8476):307310.
26. Lin LI. A concordance correlation coefficient to evaluate reproducibility. Biometrics. 1989; 45(1):255-68.

27. de la Torre CL, Ramírez-Marrero FA, Martínez LR, Nevárez C. Predicting resting energy expenditure in healthy Puerto Rican adults. J Am Diet Assoc. 2010; 110(10):1523-6. doi: 10.1016/j.jada.2010.07.006.

28. Spears KE, Kim H, Behall KM, Conway JM. Hand-held indirect calorimeter offers advantages compared with prediction equations, in a group of overweight women, to determine resting energy expenditures and estimated total energy expenditures during research screening. J Am Diet Assoc. 2009; 109(5):836-45. doi: 10.1016/j.jada.2009.02.016.

29. Siervo M, Boschi V, Falconi C. Which REE prediction equation should we use in normal-weight, overweight and obese women? Clin Nutr. 2003; 22(2):193-204.

30. Shetty P. Energy requirements of adults. Public Health Nutr. 2005 Oct;8(7A):994-1009.

31. Kien CL, Ugrasbul F. Prediction of daily energy expenditure during a feeding trial using measurements of resting energy expenditure, fat-free mass, or Harris-Benedict equations. Am J Clin Nutr. 2004; 80(4):876-80. 